\title{
The 'obvious' stuff: exploring the mundane realities of students' digital technology use in school
}

\author{
Neil Selwyn \\ neil.selwyn@monash.edu \\ Monash University, Australia \\ Selena Nemorin \\ s.nemorin@ucl.ac.uk \\ UCL Institute of Education, UK
}

\section{Scott Bulfin}

Scott.Bulfin@monash.edu

Monash University, Australia

Nicola F Johnson

nf.johnson@ecu.edu.au

Edith Cowen University, Australia

\begin{abstract}
This paper explores the ways in which students perceive digital technology as being helpful and/or useful to their schooling. Drawing upon survey data from students $(n=1174)$ across three Australian high schools, the paper highlights seventeen distinct digital 'benefits' in domains such as information seeking, writing and composition, accessing prescribed work, scheduling and managing study tasks. While these data confirm the centrality of such technologies to students' experiences of school, they also suggest that digital technology is not substantially changing or 'transforming' the nature of schools and schooling per se. Instead, students were most likely to associate digital technologies with managing the logistics of individual study and engaging with school work in distinctly teacher-led linear and passive ways. As such, it is concluded that educationalists need to temper enthusiasms for what might be achieved through digital technologies, and instead develop better understandings of the realities of students' instrumentally-driven uses of digital technology.
\end{abstract}

\section{Keywords:}

students, digital technology, digital education, high school 


\section{Introduction}

Schools are now replete with digital technologies. Students and staff bring an array of powerful laptop, tablet and smartphone devices into school. From an institutional point of view, school organization and administration is reliant on large scale 'learning management systems' and other platforms. In short, most school processes and procedures now involve (either directly or indirectly) some form of digital technology. Amidst this growing digitization of K-12 education, the use of digital technology by students has captured the imagination of educationalists - inspiring talk of 'technology enhanced learning' (Fitzgerald et al. 2018, Bayne, 2015), the 'digitally enhanced classroom' (McWilliam, 2014), the 'digitally empowered student' (Lee, 2012), and a 'new model' of school based around "openness to learning and masterful techno-savvy" (Whitby, 2013: 9-11).

A number of presumed qualities of technology-based schooling recur throughout such rhetoric. Firstly, technology use is seen to support expanded and improved forms of learning, in particular 'socio-cultural' forms of learning that are based around social interactions with others. Secondly, technology use is framed as learner-centered and learner driven - driven by personal interests and passions, and allowing flexible engagement with education that fits each individual's needs and circumstances. Thirdly, student technology use is celebrated as supporting practices that are inherently creative, communicative and collaborative in nature - what are sometimes referred to as 'twenty-first century skills' and 'connected learning' (Wortman \& Ito 2019, Ito et al,. 2013). In short, digital technologies are believed to enhance students' educational encounters and experiences in a number of empowering ways that differ markedly from 'traditional' or 'industrial era' models of schooling.

Of course, the promise of educational technology has long been stymied by an apparent reticence amongst schools and teachers to adopt and implement 'new' technologies. Throughout the 1980s, 1990 s and 2000s, computers in schools were certainly 'oversold and underused' (Cuban, 2001). Yet as we enter the 2020s, many of the obvious barriers to digital technology use throughout schools have dissipated. First, the capabilities of current technology development now matches the aspirations and ambitions of educational technologists. For example, long heralded innovations such as wireless internet connectivity and augmented reality systems are now sufficiently reliable and affordable to be mainstream consumer goods. In this manner, schools are now well resourced with a variety of powerful digital systems, applications and devices. Perhaps just as importantly, schools technology has also gained legitimacy through high-profile initiatives on the part of policymakers, IT industry and other influential actors - for example, ongoing efforts to embed programming, coding and computational thinking into school curricula; the promotion of 'Flipped Classroom' principles and the impetus of 'Bring Your Own Device' policies. The remodeling of schools around digital technology use is now a well-established and well-supported aspect of educational thinking (Cuban 2018, Lindberg \& Olofsson 2018).

Perhaps most significantly, we live in times where the majority of teachers, students, school administrators and parents are themselves adept and attuned technology users. Increasing numbers of teachers now fall into the (contestable) category of being 'digital natives' - e.g. adults born in the 1980s and 1990s who are accustomed to using digital technologies throughout their everyday lives, and have personal experience of using computers and the internet during their own schooling. Conversely, students now entering secondary school were born in the mid 2000s and have grown up in a world of smartphones, Google and Facebook - accustomed to living what Boyd (2014: 5) describes as "networked lives". Previously prescient concerns over widespread 'computer anxiety' or 'technophobia' amongst teachers and/or students no longer apply. In theory, then, we have reached a stage where the technology-based education faces far fewer impediments and barriers than was previously the case. 
Amidst these developments, surprisingly little attention has been paid to the perspectives and perceptions of students themselves, despite being the ultimate 'end users' (or at least main beneficiaries) of digital technologies in school. With this shortfall in mind, the present paper aims to develop a realistic sense of how digital technologies are now being encountered and experienced by students in school. As such, the paper addresses the following set of research questions:

- What forms of digital technology use do students report as being notably helpful and/or beneficial in terms of their schooling?

- What are the characteristics and contexts of students' beneficial technology use?

- What meanings and wider connotations related to school work and the experience of being a school student are associated with these perceived benefits?

\section{Research methods}

These questions are addressed through analysis of survey data collected as part of a mixedmethods study of technology use across three case study high schools - all co-educational, staterun public schools catering for students from 11 to 18 years in the state of Victoria, Australia. These schools were chosen to provide contrasting institutional contexts, (see Table 1):

\begin{tabular}{|l|l|l|}
\hline School A & School & Location \\
\hline & $\begin{array}{l}1170 \text { students } \\
20 \% \text { language other than } \\
\text { English } \\
36 \% \text { progress to university }\end{array}$ & $\begin{array}{l}\text { Rural area in East Victoria, bi-located in two small towns } \\
\text { (populations: } 13700 \text { and } 4500 \text { ) } \\
\text { Median household income: } \$ 900 / \text { weekly } \\
10.4 \% \text { unemployed }\end{array}$ \\
\hline School B & $\begin{array}{l}1190 \text { students } \\
30 \% \text { language other than } \\
\text { English } \\
65 \% \text { progress to university }\end{array}$ & $\begin{array}{l}\text { Median household income: } \$ 2200 / \text { weekly } \\
3.7 \% \text { unemployed }\end{array}$ \\
\hline School C & $\begin{array}{l}360 \text { students } \\
43 \% \text { language other than } \\
\text { English } \\
66 \% \text { progress to university }\end{array}$ & $\begin{array}{l}\text { Outer-city suburbs, Melbourne } \\
\text { Median household income: } \$ 1285 / \text { weekly } \\
5.7 \% \text { unemployed }\end{array}$ \\
\hline
\end{tabular}

Table 1. Institutional contexts of the school's participants

Source: The authors

Survey data was collected in two waves between September to December 2014 and February to June 2015. All students in the three schools were invited to complete an online questionnaire containing items investigating their engagement with digital technologies. The self-selecting sample of respondents comprised 1174 students. This represents an overall response rate of $43.2 \%$ (with response rates of $46.2 \%$ for School $A ; 32.9 \%$ for School B; and $67.2 \%$ for School C). As can be seen in Table 2, the resulting sample was proportionally distributed in terms of personal 
demographic and household characteristics. That said, there was over-representation of students in Grade 7 and under-representation of students in Grades 11 and 12. In addition (as is common with self-evaluations of competence), students' self-reported academic performance was skewed towards good/ very good/ excellent, with only $2.2 \%$ considering themselves to be below 'average'.

\begin{tabular}{|c|c|c|}
\hline & $\mathbf{n}$ & percent \\
\hline School A & 540 & 46.0 \\
\hline School B & 392 & 33.4 \\
\hline School C & 242 & 20.6 \\
\hline Grade 7 & 313 & 26.8 \\
\hline Grade 8 & 193 & 16.5 \\
\hline Grade 9 & 228 & 19.5 \\
\hline Grade 10 & 234 & 20.0 \\
\hline Grade 11 & 129 & 11.0 \\
\hline Grade 12 & 73 & 6.2 \\
\hline Male & 592 & 50.6 \\
\hline Female & 577 & 49.4 \\
\hline \multicolumn{3}{|l|}{ Expertise with using digital technologies } \\
\hline Expert & 173 & 14.9 \\
\hline Advanced & 498 & 42.9 \\
\hline Intermediate & 326 & 28.1 \\
\hline Beginner & 40 & 3.4 \\
\hline Don't Know & 125 & 10.6 \\
\hline \multicolumn{3}{|l|}{ Academic performance } \\
\hline Excellent & 143 & 12.3 \\
\hline Very good & 421 & 36.2 \\
\hline Good & 375 & 32.3 \\
\hline Average & 197 & 17.0 \\
\hline Poor & 26 & 2.2 \\
\hline Aspiring to continue onto higher education & 801 & 69.1 \\
\hline Not aspiring to continue onto higher education & 358 & 30.9 \\
\hline & & \\
\hline
\end{tabular}




\begin{tabular}{|l|c|c|}
\hline English only spoken at home & 707 & 74.2 \\
\hline Language other than English spoken at home & 246 & 25.8 \\
\hline Parent/ carer in employment & & \\
\hline No parent/ carer in employment & 783 & 159.1 \\
\hline & & \\
\hline Parent/ carer with higher education & 502 & 53.4 \\
\hline No parent/ carer with higher education & 438 & 46.6 \\
\hline & & \\
\hline ANZSCO occupational classification & & \\
\hline 1. Managers & 49 & 10.3 \\
\hline 2. Professionals & 157 & 33.1 \\
\hline 3. Technicians and trades workers & 96 & 20.3 \\
\hline 4. Community and personal service workers & 55 & 11.6 \\
\hline 5. Clerical and administrative workers & 16 & 3.4 \\
\hline 6. Sales workers & 42 & 8.9 \\
\hline 7. Machinery operators and drivers & & \\
\hline 8. Laborers & & \\
\hline
\end{tabular}

Table 2. Survey respondents by individual characteristics $(n=1174)$

NB. some totals do not add up to 1174 due to differing completion rates for each item.

This paper focuses on data arising from an open-ended item in the survey which asked: "Please list up to three different examples where digital technology has been really useful in helping you at school". Analysis of this data took the form of relatively straightforward thematic analysis. This involved initial readings of all responses to the open-ended survey item to gain an overall sense of the data. These data were then read again and 'open-coded' to produce an initial code list until, in the opinion of the researchers, analysis had reached theoretical saturation. Although some codes were adapted which directly used respondents' language, the majority were researcher-led and analytic. From this basis, the data were then selectively coded in terms of seventeen broader categories identified with the initial codes list directly related to the aims of the study.

\section{Results}

In total, 2539 responses were received from 906 of the survey respondents. Some of this data suggested that digital technology use was a commonplace aspect of students' everyday lives that they were not often asked to reflect upon and/or articulate. In comparison to other open-ended items in our survey, responses were often bland and somewhat passionless. Some students clearly struggled to reflect on something that was an embedded part of their school lives. For instance, one Grade 12 student's characterization of the types of digital technology that had proved 'really useful' at school was: "the obvious shit..." (male, School B). Yet as the proceeding analysis 
illustrates, taking time to unpack what might be dismissed as "obvious shit" can shed valuable light onto the actual roles that digital technologies are playing in contemporary schooling, and the meanings that are being attached to these practices.

Indeed, seventeen distinct themes were identified from the corpus of open-ended data. As table two shows, these related primarily to digital practices associated with 'doing' school work - for example, practices related to information retrieval and/or the writing of assignments and projects. Technologies were also valued as a means of contacting teachers. Tellingly, practices explicitly related to learning were reported less frequently. As will be detailed below (Table 3), some students highlighted the use of supplementary learning materials; using digital technologies as a source of ideas and inspiration; to be creative and/or to discuss work with others. Information seeking was occasionally described in terms of knowledge building or 'learning new things'. Yet the more frequently valued practices tended to be related to the practicalities of being a school student - doing class and home work, meeting deadlines, carrying school bags and so on

\begin{tabular}{|c|c|c|c|}
\hline Practice & Description & $\begin{array}{l}\text { Digital devices/ } \\
\text { applications most } \\
\text { cited in relation to } \\
\text { this factor }\end{array}$ & $\begin{array}{l}\text { Percent } \\
\text { citing }\end{array}$ \\
\hline $\begin{array}{l}\text { Information seeking } \\
\text { \& retrieval }\end{array}$ & $\begin{array}{l}\text { Online searches to retrieve facts, } \\
\text { clarifications and other discrete pieces of } \\
\text { information; sustained 'research' of } \\
\text { unknown topics - usually for an } \\
\text { assignment or project }\end{array}$ & Google & 35.7 \\
\hline $\begin{array}{l}\text { Writing \& } \\
\text { composition }\end{array}$ & $\begin{array}{l}\text { Note-taking, writing, producing } \\
\text { assignments; document planning and } \\
\text { composition }\end{array}$ & $\begin{array}{l}\text { Word, note, digital } \\
\text { camera, templates, } \\
\text { writing apps, Wordle }\end{array}$ & 23.8 \\
\hline $\begin{array}{l}\text { Contacting \& brief } \\
\text { communication }\end{array}$ & $\begin{array}{l}\text { Questions and notifications to/from } \\
\text { teachers; messaging parents and peers }\end{array}$ & Email, messaging & 22.6 \\
\hline Scheduling & $\begin{array}{l}\text { Keeping informed of deadlines, schedules } \\
\text { / time management and organization of } \\
\text { work flow }\end{array}$ & $\begin{array}{l}\text { Learning } \\
\text { management system }\end{array}$ & 12.7 \\
\hline $\begin{array}{l}\text { Basic calculations \& } \\
\text { clarifications }\end{array}$ & $\begin{array}{l}\text { Supporting numeracy, literacy and } \\
\text { language use }\end{array}$ & $\begin{array}{l}\text { Calculator, } \\
\text { dictionary, translator, } \\
\text { spelling and grammar } \\
\text { check }\end{array}$ & 12.1 \\
\hline $\begin{array}{l}\text { Accessing school } \\
\text { work }\end{array}$ & $\begin{array}{l}\text { Accessing 'work', worksheets, documents, } \\
\text { teacher-produced content }\end{array}$ & $\begin{array}{l}\text { Learning } \\
\text { management system }\end{array}$ & 10.6 \\
\hline Home working & Doing homework, working at home & $\begin{array}{l}\text { Learning } \\
\text { management system, } \\
\text { email }\end{array}$ & 8.4 \\
\hline Digital books & $\begin{array}{l}\text { Not having to carry weighty books in } \\
\text { bags; being able to store and access } \\
\text { books on one device }\end{array}$ & E-books & 8.3 \\
\hline
\end{tabular}




\begin{tabular}{|c|c|c|c|}
\hline $\begin{array}{l}\text { Supplementary } \\
\text { materials }\end{array}$ & $\begin{array}{l}\text { Alternate sources of teaching, different } \\
\text { explanations, additional information }\end{array}$ & $\begin{array}{l}\text { CrashCourse; } \\
\text { Sparknotes; Hot } \\
\text { Maths; Language } \\
\text { Perfect; Khan } \\
\text { Academy }\end{array}$ & 8.2 \\
\hline (Dis)engagement & $\begin{array}{l}\text { Avoiding being bored; filling up downtime; } \\
\text { using technology to concentrate/ remain } \\
\text { on-task }\end{array}$ & $\begin{array}{l}\text { Music, games, } \\
\text { phones }\end{array}$ & 4.6 \\
\hline Submitting work & Submitting assignments, uploading work & $\begin{array}{l}\text { Learning } \\
\text { management system, } \\
\text { email }\end{array}$ & 4.4 \\
\hline Time and pace & $\begin{array}{l}\text { Saving time, quicker, faster, getting more } \\
\text { done; Catching up on missed work }\end{array}$ & & 2.9 \\
\hline $\begin{array}{l}\text { Designing and } \\
\text { creating }\end{array}$ & Designing, CAD, making music/ videos & $\begin{array}{l}\text { Photoshop, CAD, } \\
\text { Garageband }\end{array}$ & 1.8 \\
\hline Testing & $\begin{array}{l}\text { Gauging a sense of progress, taking tests } \\
\text { \& quizzes }\end{array}$ & & 1.5 \\
\hline Inspiration & Being inspired (e.g. art); getting ideas & Google Images & 0.8 \\
\hline Image seeking & Getting images, pictures & Google Images & 0.7 \\
\hline Discussion & Discussions & $\begin{array}{l}\text { Discussion boards, } \\
\text { Facebook }\end{array}$ & 0.4 \\
\hline
\end{tabular}

Table 3. Cited reasons for digital technology being particularly useful in relation to students' school work (2539 responses from 906 survey respondents).

Interestingly, there was little distinct patterning of these themes across the survey sample. For instance, there were no notable differences with regards to students' level of educational achievement or level of technology expertise. Similarly, no differences were found in terms of language spoken, disability, or ambitions to progress to university. Only one notable gendered difference was found across the seventeen themes - with female students (27.7\%) more likely to cite the usefulness of technology-based 'Contacting and Brief Communication' than males (17.3\%). Similarly, only two notable differences were apparent along the lines of parental occupational classification. Specifically, students from managerial/professional backgrounds were more likely to cite the usefulness of technology in terms of 'Writing and Composition' $(32.2 \%$ as compared to $20.5 \%$ of students from other occupational backgrounds) and 'Contacting and Brief Communication' (35.7\% as compared to $20.5 \%$ ).

Otherwise, differences were apparent only in relation to school attended and grade of study. Here, students in school $C$ were most likely to cite the usefulness of 'Digital Books' (24.0\%, as compared to School A: 2.0\%, School B: $8.1 \%$ ). Students in School A were least likely to cite the benefits of technology-based 'Contacting and Brief Communication' (10.2\%, as compared to School B: $37.2 \%$, School C: $30.2 \%)$. One final difference in terms of school context was the steadily rising percentage of students citing the usefulness of using digital technologies for 'Accessing Work' from 
Grade Seven (5.7\%) to Grade Eleven (19.3\%). Notwithstanding these specific differences, the seventeen themes/ benefits were surprisingly evenly cited across different groups of respondents.

The nature and meanings of these themes can now be explored in more detail. The most frequently raised set of benefits centered on students' internet-based information seeking and retrieval (35.7 per cent). These practices ranged in frequency, intensity and intent. For some students, the internet was seen as most useful in supporting quick, one-off searches for specific facts, clarifications and "Googling a quick question" (school A/male/Grade 10) - e.g. "finding quotes" $B / m / 9)$; "when trying to prove facts" $(A / m / 11)$; "looking up something that you didn't have clue about" $(A / f / 7)$. These forms of information retrieval were valued for their brevity - "quick research so I don't sound like a complete idiot" (A/f/8); "you have information on the spot" (A/m/10). Such responses occasionally conveyed a willingness to rely on the internet as a repository for already 'known' information - e.g. "to find [information] that I had forgotten and needed for the topic." $(B / f / 10)$.

In contrast, other respondents described more involved uses of the internet for sustained forms of information research - e.g. to amass "unbiased study information" (B/m/12), "finding information about things I am learning about" $(\mathrm{A} / \mathrm{f} / 8)$ and generally to "know more knowledge" (C/f/11). These practices supported longer bouts of knowledge building around particular assignments and topics ranging from "Greek mythology" (C/m/7); "indigenous Aborigines" and "Cockney slang" (B/m/9). Here, then, the internet was a valued source of "learning new things" $(B / m / 11)$ and "learning something new" (A/f/9).

The second most cited benefit centered around technology-supported writing and composition (23.8 per cent). These responses also varied in their form and nature. Many highlighted the use of digital devices for quick and easy note taking - "typing up notes fast" $(B / m / 11)$ and "getting notes down faster" (C/f/11). While these practices mostly involved laptops and tablets, phone cameras were also a valued means of not having to write at all - "tak[ing] photos of notes" (B/f/9); "taking photos of work on board" $(A / f / 8)$ and "taking photos of homework (so don't have to spend time writing it after class)" (B/f/12). Other writing-related responses tended to focus on the production of longer assignments, essays and other coursework. Here technology was recognized by some students in terms of improving the presentation of their work. Respondents talked of using computers to produce "good copies of work" (A/f/9) - i.e. resulting in work that was "neater" $(\mathrm{C} / \mathrm{m} / 8)$ and "present[ed] in a neat and organized way" (B/f/8).

Other students cited the use of digital applications to support their composition of written work. Alongside the advantages of using Microsoft Word for "planning documents" (B/m/11), "easily editing essays" $(A / m / 12)$ and working with "several Word documents at once" $(C / f / 11)$, was a number of responses describing the use of labor-saving writing tools. For example, "Wordle is great for English. It makes you realize how often you repeat a word so you can improve your writing by finding synonyms" $(A / f / 12)$. Other students benefited from the use of online pro-formas and templates to give "structure, definitions and tips" $(B / f / 10)$ for their writing. Responses highlighted the use of "writing templates" $(A / m / 10)$ and even the use of "screen writing apps" $(C / f / 7)$ to guide the writing process.

A third useful digital practice highlighted by 22.6 per cent of respondents was the use of technology for 'contacting and brief communication' (as opposed to longer forms of 'discussion' which featured in only 0.4 per cent of responses). Here technology was valued as a means of quickly informing others (e.g. "when there is a problem/you are absent" [B/f/11]), and/or soliciting answers to brief questions (e.g. "when I don't understand something about the work" $[A / f / 8]$ ). While most of these responses related to email based "communicating with teachers" (B/f/11), some students also highlighted their in-school use of mobile phones to communicate with fellow students and family members. 
Throughout these responses were different descriptions depending on who was being communicated with. Teachers tended to be communicated with in terms of "contacting" (C/f/10); "notifying" (B/f/11); and "keep[ing] in touch with" (C/f/11). A number of students also framed themselves as "connecting with" (C/f/12) teachers through email. Parents were similarly described in terse, one-way terms of "notifying" and "messaging family" $(A / m / 7)$. On the other hand, communication with fellow students tended to be framed in terms of using technology to "get closer to friends" (B/f/11); "getting proper help from others" $(A / m / 10)$ and "asking my friends for help if I am unclear of what to do" (B/f/7).

Another set of benefits raised through the survey data related to managing the logistics of school work - specifically with regards to scheduling (12.7 per cent) and accessing schoolwork (10.6 per cent). For the most part, these responses related to students' management and organization of their studies through the schools' learning management system (LMS). These systems were described in ubiquitous terms - "the one place [for] all my work and information I need" (C/m/11); "we access everything via [the LMS]" (A/f/7). Student engagement with these systems was almost always described in one-way, directive language, with students being guided, informed and generally guided by the system configuration and content. As one student put it, "[the LMS] has all the work required and tells you what you need to do" $(A / m / 9)$. These systems were clearly integral to many students' ability to 'do' school. Responses described a reliance on the schools' learning management systems to "keep on track" (B/f/7); "keep in touch with our schedules" (A/f/7); "keep up with what work I need to complete I can organize what work I need to do" (A/f/11). Some students used the learning management system as a source of daily 'reminders' $(A / m / 9)$ - relying on the systems for 'just-in-time' information with regards to what each day had in store. As other students described it - "finding out what my subjects are for the day" $(\mathrm{C} / \mathrm{m} / 7)$; "checking [the LMS] in the mornings to find out what we have for each period" $(B / f / 8)$.

While the five themes just outlined accounted for the majority of student responses, a number of other digital practices arose throughout the survey data. For example, one set of issues related to what might be characterized as prosaic but clearly important parts of school work. Particularly prominent were responses relating to forms of basic calculations and clarifications (12.1 per cent). These described students' use of calculators, translators, spelling and grammar checks, and dictionary tools. Such applications were all basic but clearly valued uses of technology - for example, as one student enthused of online dictionaries: "makes my English sound excellent by finding a better vocabulary of words" $(A / m / 10)$. A number of students also raised the convenience and flexibility of digital books (8.3 per cent) as opposed to physical text-books - primarily in terms of being relieved of the burden of "hav[ing] to carry all the big massive normal text books" $(\mathrm{C} / \mathrm{m} / 7)$. Also in this vein were responses describing the convenience of being able to continue accessing materials and working on school assignments when at home (8.4 per cent) and also submitting work (4.4 per cent) regardless of time or location.

Less procedural, perhaps, was the use of technology to access supplementary materials and alternate sources of education ( 8.2 per cent). These responses related to students using nonapproved resources for additional and/or alternate tuition - providing "more explanation/ more understanding" $(A / f / 10)$ of subjects that were being studied in school. A range of these resources were detailed in the survey data - "online tutorials" $(A / m / 12)$; summary "videos such as those posted by CrashCourse" (B/f/12); "Khan Academy" (B/m/11); "Sparknotes for English" (B/f/10); "Hot Maths" (B/m/7); "Language Perfect in Japanese" $(B / m / 7)$; and various other "online learning programs" $(B / f / 7)$. In all these cases, students valued the applications' "help in clarifying things I didn't understand in class" (B/f/12) and "get[ting] better explained examples of work when I don't understand what my teachers are trying to say" (A/f/11). Often these technologies were used to access alternate views and opinions, either to "consolidate theory being taught in class" (C/m/11) or (more pointedly) as a means of "proving the teacher wrong" $(B / m / 12)$. 
In contrast to these examples of self-directed learning, was the role of technology in helping students deal with episodes of (dis)engagement with their work (cited by 4.6 per cent of respondents) - i.e. alleviating boredom and/or sustaining concentration and engagement with school work. Here technology was a useful means of "keeping me entertained" (A/f/9) on occasions "when you don't know what to do" (A/m/7). One student highlighted the pleasures of "playing games while waiting in class for the teacher to arrive." $(\mathrm{C} / \mathrm{m} / 7)$. In these cases, technology was a valued means of providing respite and "distraction" $(A / m / 8)$ from lessons: "I won't get bored by just listening to the teacher speak the whole lesson" (A/f/10); "filling in time where I get bored or stressed in class" $(A / m / 10)$. While generally centered on the avoidance of work, a few respondents attempted to frame these uses of technology in a more productive sense. As these justifications for listening to music on smart phones contend: "providing music so I can zone out and get my work done" $(A / f / 10)$; "listening to music to help me concentrate" $(A / f / 8)$.

A final set of issues (cited by only a handful of respondents) related to what might be described as more individually-driven and/or innovative uses of technology. These included the benefits of technology to control the time and pace of one's work (2.9 per cent) - most prominently the ability for "multitasking" ( $\mathrm{A} / \mathrm{m} / 8)$; "saving time" $(\mathrm{B} / \mathrm{m} / 7)$; "if I finish one topic I can go onto the next, instead of having to wait for the rest of the class to finish" (A/f/10). Another aspect of this temporal flexibility related to "catching up on things that I have missed" $(A / m / 10)$, whether due to missing lessons or simply wanting to "read back on PowerPoints from class" (A/f/10). Elsewhere, a few students cited their uses of technology for designing and creating (1.8 per cent) videos, music, computer aided design, "photography and digital photo editing" (B/m/11). A few students also raised the use of technology to gauge a sense of progress ( 1.5 per cent) by using online tests, quizzes, "finding examples of high scoring essays" (B/f/12); "checking my reports and progress" $(A / f / 12)$, and generally being able to "assess how I am going in my school work" (A/f/11). Seven of the 906 respondents ( 0.8 per cent) highlighted the use of technology for "finding inspiration" $(\mathrm{C} / \mathrm{f} / 10)$ and "getting ideas" $(\mathrm{A} / \mathrm{m} / 8)$.

\section{Discussion}

Our research confirms digital technologies to be an integral part of how students encounter and engage with their schools and school work. Many of the practices and procedures described in our study constitute sophisticated uses of technology that would have been unimaginable twenty years before. As such, digital technology are clearly associated with substantial changes to the ways in which students experience their studies. Yet our analysis also suggests that digital technologies are not transforming or disrupting the 'student experience' and what it means to study at school, especially when compared to the (sometimes radical) claims made on behalf of educational technology. In contrast to recent enthusiasms for connected, personalized, social and/or creative student practices, the technology use most prevalent in our data was that of 'information' and 'communications'. While a few responses did convey the value of using digital technologies in more expansive, creative and/or collaborative ways, this would not appear to be what is proving to be of actual benefit for the majority of school students.

Thus, while our investigations set out to focus on 'best practice' and 'most useful' aspects of technology use, the resulting data are perhaps more insightful in illustrating the bounded nature of students' uses of digital technology within schools. In this sense, our data add to a recent acknowledgement elsewhere in the literature of the 'ambivalent' nature of digital technology use by school students (e.g. Aagaard 2018, Watkins et al. 2018). Many of the ostensibly 'educational' 
benefits of digital technology reported in this paper relate to the 'logistics' of school work rather than matters related directly to 'learning' per se. Despite being given a free reign in their answers, most respondents chose to highlight the benefits of using digital technology in order to complete assignments, coursework, homework and other projects set by their teachers. Digital technologies are clearly integral to students' ability to conduct information research, write up and then submit their work. These task-based activities are understandably core elements of the 'job' of being a school student, but have little correspondence with the dynamic practices that often drive enthusiasms for the educational potential of digital technologies. Thus, much of what students were finding to be 'most useful' about digital technologies related to the rather mundane practices that are required to be 'successful' at school - i.e. taking individual responsibility for one's studies, being organized in terms of time/work, following rules and structures (Blanco \& RodríguezMartínez, 2015).

On one hand, then, these responses might be celebrated as evidence of students' strategic and pragmatic adoption of digital technologies in ways that allow them to negotiate their school commitments. In current educational parlance, our data could be seen as evidence of students' 'resilience', 'grit' and/or 'buoyancy' in curtailing their more free-ranging and social uses of digital technology to the specific demands of the school context, therefore making best use of technologies to progress 'through the system' (Lumby, 2012). Certainly, for many respondents, any notion of technology-supported 'learning' was framed in terms of 'instrumental' rather than 'inherent' benefits - i.e. focused on procedural rather than creative or critical outcomes (Griffths, 2012). Respondents most often framed technology practices as externally imposed and replicating a dominant 'transmission' culture of teaching and learning, i.e., what Lawson and Lawson (2013: 445) characterize as "something that is inherently passive and needing to be stimulated by a teacher". The digital practices that were most often cited as 'useful' by students, therefore, related to largely passive, compliant and responsive forms of engaging with prescribed study goals.

As such, students' uses of digital technologies (and perceptions of 'what works' best) appear to be shaped by the school and classroom contexts within which students are situated as much as they are the result of individual 'choice' and agency and/or any supposed 'affordance' of the digital technology. The 'beneficial' digital practices highlighted in this study offer a telling reflection of the realities of contemporary schooling and the contemporary student experience. Digital technologies are therefore implicated in the ways that the demands, stresses and increasing workloads of contemporary schooling result in what Smyth and Banks (2012: 282) describe as "a strong preference for a more narrowly focused approach" to doing things. Thus, the types of technology use highlighted in our survey need to be understood within the wider contexts of Australian secondary education - in particular the emphasis on high stakes testing, narrowing of the curriculum, fragmentation of subject knowledge and encouragement of "low-level thinking and promoting outcome measures rather than the intrinsic processes of learning and acquiring knowledge" (Polesel et al., 2012: 5).

Set within these conditions, it is perhaps understandable that many students see most benefit in 'playing by the rules' to achieve educational success (Smyth \& Banks 2012: 287). Of course, such an approach is not unique to technology use but can infuse all aspects of students' conduct - from the 'learner identities' they develop to the relations that are formed with other students and teaching staff. Seen in this way, the limited forms of digital practices highlighted in our data are best understood as those that 'fit' the rather limited expectations and processes that currently constitute school teaching and learning. For example, if student accountability is framed primarily in terms of the ability to 'research' and produce sole-authored assignments, then many students understandably will approach their use of digital technologies along such lines. In this sense, the 'useful' uses of digital technologies highlighted within our survey data are those that are legitimized through wider institutional regimes - such as the expectation to attend timetabled classes, to 
regularly produce coursework assignments, and generally adhere to the institutional expectations of being a compliant school student.

\section{Conclusions}

Our study fits a recent trend for education research based upon the straightforward act of "listening to young people and communicating what is heard" (Lumby, 2012: 266). Paying particular attention to students' actual experiences of digital technology and the meanings associated with them therefore provides an alternate basis for questioning and challenging some of the assumptions that tend to pervade discussions of schools and technology (Olofsson et al, 2018). Of course, this study is limited in terms of its explanatory, descriptive and self-report nature - all of which leads to an inevitably broad-brush nature of analysis. While it is notable that few distinct demographic differences were evident in terms of the frequency of survey responses, this does not imply that technology engagement is somehow free from being patterned along lines of social class, gender and so on. There will be numerous disparities and delineations in the issues raised from the open-ended survey data that will require more socially-sensitive methods of inquiry.

Nevertheless, having offered an expanded sense of what students have to say about digital technology in school, we now face the question of what - if anything - needs to be 'done'. As has just been illustrated, many students are certainly finding uses of digital technologies that they feel work well for them within the context of their school studies. However, these uses and practices are clearly not the most expansive, empowering, enlightening or even exciting ways that digital technologies could be used. In one sense, then, it is reasonable to conclude that schools have an obligation to continue to support these useful but restricted aspects of students' digital studies. For example, schools would be well-advised to continue to improve the reliability and 'user-friendliness' of their learning management systems, teacher use of email and support for student information seeking. While it is not the most innovative conclusion to reach, our data certainly make a strong case for doing the boring things better (i.e. continuing to pay attention to improving the 'obvious shit').

Conversely, our data suggest that any enthusiasms for more expansive forms of digital technology use (especially on the part of academics, industry spokespeople and other members of the educational technology community) are perhaps irreconcilable with the current norms of schools and schooling. In particular, this raises the need for such proponents of education technology to think more carefully about how broader institutional practices and expectations are shaping the 'what' and the 'how' of digital technology in schools. More attention might perhaps be paid towards how institutional cultures and assumptions of curriculum, assessment, accreditation and so on 'mesh' with other (often external) expectations of technology-based reforms of school. If educators wish to see students move beyond the largely instrumental, 'safe', bounded and outcome-focused uses of digital technology reported in this paper, then alternate contexts of teaching and learning need to be legitimized where alternate (perhaps more active, more participatory or more creative) uses of digital technology would be of genuine 'use' and 'help'.

As these latter suggestions imply, perhaps the main conclusion to emerge from our investigations is that technology-based change in education is not inevitable. In the first instance, people will always tend to use technologies to carry on doing what they previously have done. In this sense, the forms of digital technology use that students report as being notably helpful and/or beneficial in terms of their schooling are understandably prosaic - the 'obvious' stuff of schooling and being schooled. While there is a strong emphasis on studying, there is less sense of learning. In this sense, students' engagement with technologies is shaped by the contexts of contemporary 
schooling - the need to produce work that can be assessed, the need to be self-organized and able to engage with schoolwork on a flexible basis. These perceived benefits suggest an understanding of schooling as a relatively ordered, procedural affair - far removed from notions of digital 'disruption', 'serious fun' and other educational technology tropes. Thus, the most common digital practices are those that involve technology being used in ways that fit around established institutional arrangements and organizational cultures. In this sense, these are the issues that proponents of educational technology need to be discussing, debating and focusing their attention on. Any substantial shifts in the nature of schools and schooling will be incremental and not driven by new technologies alone ... however connected, convenient or flipped they might be.

\section{Acknowledgments}

This work was supported by the Australian Research Council [grant number DP140101258].

\section{References}

Aagaard, J. (2017). Breaking down barriers: The ambivalent nature of technologies in the classroom. New Media \& Society, 19(7), 1127-1143.

Bayne, S. (2015). What's the matter with 'technology-enhanced learning'? Learning, Media and Technology, 40(1):5-20.

Blanco, N. \& Rodríguez-Martínez, C. (2015) Attitude and commitment to school of successful secondary school students. Journal for the Study of Education and Development, 38(3):542-568.

Boyd, D. (2014). It's complicated: the social lives of networked teens. New Haven CT, Yale University Press.

Cuban, L. (2001) Oversold and overused. computers in the classroom, Cambridge, Harvard University Press

Cuban, L. (2018). The Flight of a Butterfly or the Path of a Bullet? Using Technology to Transform Teaching and Learning. Cambridge, Harvard University Press

FitzGerald, E., Kucirkova, N., Jones, A., Cross, S., Ferguson, R., Herodotou, C. \& Scanlon, E. (2018). Dimensions of personalisation in technology-enhanced learning. British Journal of Educational Technology, 49(1), 165-181.

Griffiths, M. (2012) Why joy in education is an issue for socially just policies. Journal of Education Policy, 27(5):655-670.

Ito, M., Gutiérrez, K., Livingstone, S., Penuel, B., Rhodes, J., Salen, K., Schor, J., Sefton-Green, J. \& Watkins, S. (2013). Connected learning: an agenda for research and design. Irvine CA, Digital Media and Learning Research Hub

Lawson, M. \& Lawson, H. (2013). New conceptual frameworks for student engagement research, policy, and practice. Review of Educational Research, 83(3):432-479.

Lee, M. (2012) Waste, technology, 24/7/365 teaching and collaborative development. Australian Teacher Magazine

Lindberg, J, and Olofsson. "Recent trends in the digitalization of the Nordic K-12 schools'. Seminar. net, 14(2), 103-108

Lumby, J. 2012. Disengaged and disaffected people: surviving the system. British Educational Research Journal 38(2): 261-279.

McWilliam, E. (2014). Pedagogical relations in the age of big data. Access, 218(1):6-12. 
Olofsson, A, Lindberg, O. \& Fransson, G. (2018). Students' voices about information and communication technology in upper secondary schools. The International Journal of Information and Learning Technology, 35(2), 82-92.

Polesel, J., Dulfer, N. \& Turnbull, M. (2012) The experience of education. Sydney, Whitlam Institute

Smyth, E. \& Banks, J. (2012). High stakes testing and student perspectives on teaching and learning in the Republic of Ireland. Educational Assessment, Evaluation and Accountability, 24(4):283-306.

Watkins, S., Lombana-Bermudez, Cho, A., Shaw, V., Vickery, J. amd Weinzimmer, L. (2018). The digital edge: How black and Latino youth navigate digital inequality. New York, NYU Press

Whitby, G. (2013). Educating gen wi-fi. Sydney, ABC Books

Wortman, A, and Mizuko I. (2019) "Connected Learning." in Hobbs, R. and Mihailidis, P. (eds) The International Encyclopedia of Media Literacy. Hoboken NJ, Wiley-Blackwell 